\title{
Atypical global Takotsubo syndrome in a patient with acute disseminated encephalomyelitis
}

\author{
John E. Madias ${ }^{1,2}$
}

Received: 16 February 2016/ Accepted: 16 February 2016/Published online: 18 March 2016

(C) Springer-Verlag Berlin Heidelberg 2016

To the Editor:

The report by Venkatraman et al. [1], published on line ahead of print on February 12, 2016 in the Journal, about the 29-year-old man with acute disseminated encephalomyelitis (ADEM) and precipitated Takotsubo syndrome (TTS) is of great interest, because it highlights the condition occurring in a young male, who suffered transient left ventricular atypical global hypokinesis, in association with ADEM with brain magnetic resonance imaging (MRI)-detected multiple T2-hyperintense lesions, affecting primarily the medulla oblongata. Since the clinical syndrome had started 3 months prior to presentation it is conceivable that other variants of TTS (particularly reverse TTS, known to be frequent in young males) had been present prior to the detection of the global TTS.

The observed perturbations of blood pressure and heart rate are in keeping with enhanced stimulation by the sympathetic and vagal autonomic nervous system associated with TTS as previously discussed [2, 3]. Indeed, the vagal implication is in this case due to the extensive medulla oblongata involvement since this brain structure is the "home to multiple cranial nerve nuclei and large parts of the reticular formation, and is involved in autonomic regulation of heart rate, blood pressure and breathing" [1].
The electrocardiogram (ECG) of Fig. 1 [1] shows generous QRS complexes in this patient, in keeping with his sex and African-American race, and since TTS has been associated with transient QRS voltage attenuation (attQRS) [4], it will be of interest to inquire whether subsequently recorded ECGs revealed attQRS.

\section{Compliance with ethical standards}

Conflict of interest None.

\section{References}

1. Venkatraman A, Bajaj NS, Khawaja A, Meador W (2016) Cardiogenic shock from atypical Takotsubo cardiomyopathy attributed to acute disseminated encephalomyelitis lesion involving the medulla. Clin Auton Res. doi:10.1007/s10286-016-0346-x

2. Samuels MA (1993) Neurally induced cardiac damage. Definition of the problem. Neurol Clin. 11(2):273-292

3. Samuels MA (2007) The brain-heart connection. Circulation. 116(1):77-84

4. Madias JE (2014) Transient attenuation of the amplitude of the QRS complexes in the diagnosis of Takotsubo syndrome. Eur Heart J Acute Cardiovasc Care. 3(1):28-36

John E. Madias

madiasj@nychhc.org

1 Icahn School of Medicine at Mount Sinai, New York, NY, USA

2 Division of Cardiology, Elmhurst Hospital Center, 79-01 Broadway, Elmhurst, NY 11373, USA 